\title{
Exceptional Senior Student Affairs Administrators' Leadership
}

\author{
by Gwendolyn Jordan Dungy and Shannon Ellis (Eds.)
}

Published by NASPA, 2011, 320 pages

Reviewed by

Rich Whitney (rwhitne5@depaul.edu) is an Assistant Professor at DePaul University.

If one were to read the book Exceptional Senior Student Affairs Administrators' Leadership as a how-to-be-an-SSAO manual, the whole topic could be a bit overwhelming. Trying to combine all of the information and descriptions offered by these contributors creates a paragon of an administrator that most would be hard pressed to emulate. It would give the phrase "waiting for Superman (or Wonder Woman)" a completely new meaning; however, if the reader uses this book as a way to understand the view from the top and to delve into sage observations from leaders who want to illuminate the potential for the next generation to follow, then this book is a great resource for any practitioner.

In this book, Gwen Dungy and Shannon Ellis have gathered a panel of experts who offer their thoughts on leadership and professional development. The contributors represent a cumulative 840 years, approximately, of experience in higher education and student affairs. With an average of about 30 years each, these 28 contributors have been university presidents, vice presidents of student affairs and academic affairs, faculty, senior student affairs administrators, and consultants.

Each chapter expands the conversation even more through illustrations of the authors' personal experiences, as well as numerous examples from colleagues from the United States and throughout the world. These authors and contributors model the seven enduring competencies of leadership posited by the entire volume.

Authors Dungy and Ellis articulate in the preface of the book that they were inspired by an observation that the path to the presidency of an institution is primarily through the faculty route. Admittedly, this faculty route has been regarded as the venerable ascension to the highest office, but the authors suggest this assumption could-and should-be challenged. The 11 chapters of Exceptional Senior Student Affairs Administrators' Leadership have been organized into a systematic walk through the landscape of higher education. There are two different types of chapters used in the book: the typical chapter addressing one topic or application and the chapter that includes smaller sub-chapters that provide a richer conversation around their subject. There is a cadence created with the layout of the book. The first three chapters serve as an introduction; the middle includes the 
chapter/sub-chapter effect, separated by a pivot chapter, followed by three future directions chapters; and the book concludes with a synthesis.

The book suggests it is prudent that all working professionals, especially those aspiring to be Senior Student Affairs Officers (SSAOs), need to learn how to focus on current events while anticipating what the future may hold. Rather than starting with a history lesson to bring context to the book, the first three chapters of Exceptional Leadership set the context by looking at the here and now with an eye on the future. Chapter 1, "The New World of Student Affairs," touches quickly on the history, ending with a contemporary view. Chapter 2, "Don't Fence Me In: The Senior Student Affairs Officer in the 21st Century Community College," adds additional venues to the conversation about our field today. In Chapter 3, "Student Affairs Leadership in a Networked Knowledge Era," the authors center the discussion on leadership, noting the significant shift from a hierarchical to a networking approach that is occurring in the field; furthermore, they note that this relational collaboration approach is occurring within the global knowledge era and is important in the dynamic roles of student affairs today. The chapter ends by suggesting that the future SSAO will need to be attentive to the nuance of change and complexity to provide effective leadership.

Chapter 5, "The New, New Senior Student Affairs Officer," seems to serve as the fulcrum for the book and helps to balance the chapters' content and types with all of the strategies and competencies cumulatively offered by all of the contributors. Here, Ellis sets the stage for the book that is adroitly summed up by Dungy in the final synthesis chapter. She begins the chapter with a discussion about the difference between "new" and "new, new" to provide an explanation for the chapter title. "New means fresh...typically unknown" (p. 101). "New, new" positions the new leaders within student affairs as innovators at the institution that "create the professional edge" (p. 101). This middle chapter addresses the need to be self-aware, how to act like a long-timer, inspire excellence, develop relationships, and think and act strategically. This chapter suggests that readers look within, in addition to taking an external look at their divisions and institutions.

Chapters 4, 6, and 7 are the chapter/sub-chapters where 16 of the contributors share their thoughts about SSAO leaders at different institutional types (Chapter 4), competencies needed (Chapter 6), and the road to the presidency (Chapter 7). The three larger chapters offer introductory remarks complemented by the subchapters to expand the main topics to greater proportions. The 16 mini chapters all provide examples, stories, and counsel from experts who have been there and seen the changes to the higher education landscape over a remarkable number of years.

The latter section of Exceptional Leadership (Chapters 8, 9, and 10) continues to press the issue of creating future leaders in the profession that understand the need for student affairs to contribute to the student experience, while remaining attentive to their contributions to the institutional mission. Much has changed in the day-to-day activities of the student affairs professional since the initial writing of the Student Personnel Point of View in 1937; however, the vital role of the profession and the contributions we make to the college student experience 
remains true. The influence of the United States on student affairs around the world and the understanding that "we can learn from them as well" has expanded our roles, while also illustrating the compactness of our current world and profession. As agents of hope, the SSAOs also have two planes to contemplate: what they hope for themselves and what they hope for their students. This goaldirected behavior leads to creating opportunities for student engagement and the hope for achievement.

In the final chapter, Gwen Dungy does a great job of connecting the material by synthesizing 840 years, 320 pages, and 28 contributors into seven enduring competencies. She weaves many of the concrete examples and all of the chapters together into the following threads of leadership: responsibility and accountability; learning from personal and professional experiences; power of knowledge; listening and communicating; functioning in a large, networked universe; collaborations, partnerships, and relationships; and innovation and creativity. She acknowledges that many of the leadership skills "have yet to be identified" (p. 275) and the onus is on student affairs administrators "to demonstrate what they bring to the academic enterprise" (p. 283). She notes that some of this is due to the fact that many outside of the profession have a hard time understanding the roles and jobs of student affairs people. Dungy reiterates common words expressed by many of the contributors by acknowledging that the future holds two things: more complexity and the impact of today's decisions.

Exceptional Senior Student Affairs Administrators' Leadership is admittedly written for the aspiring senior administrator who may be seeking the answers to the questions, "where am I going?"; "where could I go?"; or "where do I want to go?"; however, the utility of this book reaches further into the field. Borrowing from one of Stephen Covey's Seven Habits, starting with the end in mind, this book could also be useful for newer professionals contemplating their overall career goals in higher education and student affairs. The competency of collaboration and relationship building was evident in many of the comments by the contributors. Self-knowledge and possessing the ability to connect all of the dots and anticipate the multiple scenarios SSAOs must deal with on many fronts will be required of all competent student affairs practitioners. This book helps to reveal some of the strategies and competencies for success, but as we all know, those could change tomorrow. 